\title{
Analyzing risk factors for highway theft in Mexico
}

\author{
E. de la Torre ${ }^{1}$, C. Martner ${ }^{1}$, J. Martínez $^{2}$, E. Olivares ${ }^{2}$ \\ \& E. Moreno ${ }^{1}$ \\ ${ }^{1}$ Mexican Transportation Institute, Mexico \\ ${ }^{2}$ Popular Autonomous University of the State of Puebla, Mexico
}

\begin{abstract}
In recent years thefts in the Mexican trucking sector have increased, causing huge losses to carriers, so a study to know the risk factors faced by the motor carriers seems pertinent. Security is a relatively recent topic in logistics and supply chain studies, mainly based on conceptual views and qualitative data on operational disruptions in the supply chain and security issues related to terrorism. This article aims to identify variables influencing the risk of trucking robbery in Mexico, providing information to facilitate security assessments of freight, and the planning of security schemes for companies. To identify these risk variables a statistical analysis of the available national information on freight thefts is done, determining a first set of variables to design a survey applied to experts in supply chain security based on the Delphi method. Results allow us to confirm the variables or suggest new ones, showing their influence on the risk. Keywords: supply chain risk, security, theft.
\end{abstract}

\section{Introduction}

Since the late twentieth century, security and risk in the supply chains has been addressed around the world; however the number of works is still reduced especially on trucking theft, even while the articles on logistic and supply chain have grown steadily. The importance of this topic is evidenced by the safety initiatives and certifications, which emphasize its impact in the supply chains. Some authors identify the need of research to understand, identify and quantify the risk in the supply chain to improve its management, with both conceptual and methodological contributions. Some of these contributions are as follows. 
Sheffi [1] gives an introduction to understand supply chain risks, particularly, those tied with terrorism, giving some ideas to improve the design of the supply chain. Martha and Subbakrishna [2] discuss the risk on the supply chain, and the importance of developing chains ready to recover from perturbations.

Other studies $[3,4]$ give similar ideas by comparing the security of the supply chains with the total quality management. Lewis et al. [5] deal with operative response techniques for security processes and interruptions. Luedtke and White [6] consider the visibility in the actives of the supply chains, both rigid and flexible activities. Bainman et al. [7] discuss the mechanisms of collaboration to guarantee the security in a supply chain.

Willis and Ortiz [8] give a reference framework for the evaluation and management of security in the supply chain. They focus mainly on improving security and efficiency of the chain in the intermodal transport, to prevent terrorist attacks. Tsamboulas and Moraiti [9] designed a multicriteria model to evaluate the risk of the international supply chains to prevent terrorist acts.

Chopra and Sodhi [10] classify risk and the leading factors on the supply chain. Transport risks, are attributed both to permanent and temporal interruptions by various factors, such as congestion, natural catastrophes, and terrorism. Meanwhile, Uhlig [11] holds that in general, authors do not deal transport interruptions as a separate risk category, showing that more research is needed.

Wilson [12] distinguishes two types of interruptions: general and transport related. The latter referring to any interruption of the goods flow, while others include, by example, interruptions in manufacturing of products. He examines the effects of transport interruptions in the performance of the supply chain, using system dynamics in two chain scenarios. Tsuchiya et al. [13] and Huang et al. [14] apply simulation to evaluate similar cases. Other investigators analyze earthquakes and other natural catastrophes as sources of transport interruptions and their impact on the economy (Takahashi et al. [15] and Okuyama et al. [16]).

The literature review showed that just a few authors identify risk factors, and even a less number, those measuring the impact of interruptions in the supply chain, like transport. As an example, Rodrigues et al. [17] investigate the impact of the uncertainty in transport operations in the supply chains, but they do not quantify the transport interruption impact.

\section{Security in the supply chain in Mexico}

Security in the supply chain is a vast field with many gaps still because of the great number of links in the supply chain, and their different types of risk. At least in the trucking, there is no null risk, but it is possible to study, identify and analyze the main risk factors to modify them, preventing or mitigating its impact.

The type and level of risk is different for international supply chains from for those in a local environment. In Mexico, according to Cedillo [18], the entrepreneur's perception puts the main risks firstly on drug trafficking, then the theft to trucking, followed by smuggling and human smuggling. Generally the perception of the type and level of risk is not the same for all countries, so 
measures that result effective in a country may not be effective in another, due to economic, politic, social, and cultural characteristics differences.

This work is a first approach in the analysis of trucking theft. Mainly because it is an issue with poor statistic information, but with the chance of research under the view of entrepreneurs and experts on the topic, to identify the principal factors affecting the risk of shipments robbery. The aim is to contribute to evaluate the shipments risk with different features, and information on theft risk, to help avoiding overinvestment in security affecting companies' profits without incurring in losses by a subjective underestimate of the risk.

\section{Research methodology}

The identification and analysis of the sources of risk and its influence in the trucking theft in Mexico, was based on interviews to carriers and users of the freight service and as well to security experts in the supply chains. Multivariate analysis of robbery data in Mexico was examined as a complement. Interviews applied to 17 companies to know their perceptions on cargo robbery and how they evaluate the risk in the supply chain produced the first ideas on risk factors.

The Delphi Method was found as the most adequate methodology to apply, because available information was insufficient, and there were strong divergences between statistical sources and the companies' interviews according to region, type of goods moved and company size, among other factors.

Theft statistics from Mexico City were used for analysis of principal components (ACP). ACP results were discussed with five experts with at least ten-year experience in supply chain risk management, and included in the Delphi Method exercise. The first stage of Delphi Method yielded feedback on the relevance of the variables in the robbery risk, and extra variables were added by the experts. In the second stage of Delphi Method, experts selected the five key variables assigning a weight with base 100 . Factors were rated according to the number of experts selecting each factor and the average weight given by the experts.

According to Li et al. [19], security problems have three basic characteristics: they are complex, they are dynamic on time and they have no information. Truck robbery shows these three characteristics; the first alternative for the lack of statistic data was to interview to entrepreneurs, however, considering the findings of Puljić [20] the subjective evaluation of risk performed by them can have cognitive biases giving a risk evaluation distinct from the real one.

To improve the identification of factors, information obtained from entrepreneurs was complemented, by doing interviews to experts on security of transport, following Jessup's methodology (Jessup et al. [21]) who seeks to determine the costs of implementation of the security measures. The experts rated the factors given by the entrepreneurs, according to its relevance, proposing some others factors not considered by entrepreneurs. The consensus of the opinions of the experts was obtained through the Delphi Method. An additional source of thefts to trucking is the Statistics of Theft by State, published by the company Recurso Confiable [22] with information about streets, cruises, day of 
the week and type of vehicle from theft reports. With this information a main components analysis was made to identify the most relevant factors on the incidence of the thefts.

\section{Results}

After the interviews and the Delphi analysis, the main risk factors, types of impacts and factors discouraging the theft were identified. It was found that the type of merchandise and the human factor were those of most risk, while regarding impacts, the compliance failure to the customer and the loss of market were the most important once the interruptions emerge.

During the application of interviews to carriers and users it was corroborated that subjective evaluation, referred by Puljić [20], appeared on their perception from previous experiences. Companies without thefts in the last two years considered their probability of suffering it in the future as zero $(0 \%)$ while those that had suffered thefts in the past two years rated their probability over $50 \%$, in spite of the stolen cargo percentage did not approach even distantly to such proportion.

\subsection{Factor identification}

The list of possible risk factors obtained, is shown in Table 1. First column indicates the factor and in the rest it is indicated the source for the variable identified as a risk factor. The column labeled "Statistic data" refers to theft statistics from Recurso Confiable [22] and Freight Watch [23]. The column named "Entrepreneur" shows factors identified in the interviews to carriers and users of the transport service and the last column presents the experts opinions.

Table 1: $\quad$ Factor identification.

\begin{tabular}{llll}
\hline Factor & Statistic data & Entrepreneur & Experts \\
\hline Route & Yes & Yes & No \\
\hline Zone & Yes & n.d. & Yes \\
\hline Size of vehicle & Yes & n.d & Yes \\
\hline $\begin{array}{l}\text { Type of } \\
\text { merchandise }\end{array}$ & Yes & Yes & Yes \\
\hline Human factor & n.d. & Yes & Yes \\
\hline $\begin{array}{l}\text { Free highway or } \\
\text { fee }\end{array}$ & n.d. & n.d. & Yes \\
\hline
\end{tabular}

n.d. = No data.

\subsubsection{Route}

Interviews to carriers and users of the trucking service, suggested the route as the main factor. However, ACP did not support this idea. To clarify this, interviews to companies with success stories in reducing thefts were done. It was found that route change did not reduce thefts, at least in the long term because companies 
which changed routes did not reduce robberies significantly, since quickly this new route became equally problematic. An explanation from experts suggested that the route is not a risk factor as such, since a criminal group is not positioned at a certain point in the road to steal vehicles, it rather works by demand, looking for a known shipment, probably selected by leaking information from the company itself.

\subsubsection{Conflictive zones}

Criminal groups operating in certain regions have caused insecurity for the transport of goods in the country by creating hot spots for cargo carried. This factor proposed by some companies and confirmed by half of the experts could explain the perception of the entrepreneurs on the importance of the route, by changing to the perspective of the zone, since the presence of criminal groups on the region is less volatile, because they easily carry out the theft by readjusting its localization of target shipments in its zone.

\subsubsection{Size of the vehicle}

A factor absent on the interviews to companies was the type of vehicle. ACP on the vehicular type suggests more theft on smaller vehicles; this coincides with the opinion of the experts, about that unit trucks are stolen more commonly because it is easier to break down the cargo and quickly distribute small shipments than big shipments. Criminals prefer flexible and quick operations, so choose to steal rather small shipments.

Figure 1 shows ACP results with Mexico City's theft data 2010 from the source Recurso Confiable [22]. Vehicle types considered were: Articulated, 3.5tons truck, 2-Axles truck, 3-Axles truck and 1.5-tons Pickup. The three first components explain $96.2 \%$ of the variance in the number of thefts. These components show negative correlation with articulated vehicles. The first principal component PC1 contrasts the preference of robbery to 2-axle vehicles versus articulated ones; the second principal component PC2 shows positive correlation for robbery to 3.5-tons truck and a negative correlation to 3-axles vehicles, and the third principal component PC3 shows a strong correlation to robbery to 1.5-ton Pickups. All together shows a preference or robberies to small and medium capacity vehicles versus the articulated ones.

$\begin{array}{lrrrrr}\text { Eigenvalue } & 2.7710 & 1.1758 & 0.8609 & 0.1923 & 0.0000 \\ \begin{array}{l}\text { Proportion } \\ \text { Cumulative }\end{array} & 0.554 & 0.235 & 0.172 & 0.038 & 0.000 \\ & & 0.789 & 0.962 & 1.000 & 1.000 \\ \text { Variable } & \text { PC1 } & \text { PC2 } & \text { PC3 } & \text { PC4 } & \text { PC5 } \\ \text { Artic } & -0.569 & -0.176 & -0.259 & 0.222 & 0.727 \\ \text { Truck3.5 } & 0.442 & 0.612 & 0.071 & -0.258 & 0.598 \\ \text { 2-axle } & 0.545 & -0.210 & 0.047 & 0.796 & 0.149 \\ \text { 3-axle } & 0.318 & -0.738 & 0.207 & -0.478 & 0.289 \\ \text { Pickup1.5 } & -0.287 & 0.078 & 0.940 & 0.146 & 0.084\end{array}$

Figure 1: Analysis of main components for size of the vehicle 


\subsubsection{Type of merchandise}

Merchandise type was identified by experts as a risk factor due to the existence of regular demand of products of high value, like clothing, sport shoes, etc. These goods' brands and those products with high economic density acquire a value greater than just the manufacture cost. In these cases risk is tied to the existence of a grey market (or parallel market), i.e., distribution channels which, while legal, are unofficial or unintended by the original manufacturer where goods are offered with a lower price compared to the formal market.

Statistics show that goods with higher theft incidence are finished products, which agrees with the opinions of experts and entrepreneurs shown in Table 2. However, some companies also reported raw materials thefts. This suggests that tracing of stolen raw materials requires research since some of them are of specialized management and of difficult deconsolidation for its sell on retail in the grey market. This could confirm the opinions of experts who claim that many of these thefts are carried out on request and not in a random way.

Table 2 shows the most stolen products in the year 2010 in Mexico, according to the company Freight watch.

Table 2: $\quad$ Most stolen products during the year 2010.

\begin{tabular}{ll}
\hline Food and beverages & $22 \%$ \\
\hline Construction & $18 \%$ \\
\hline Automobile parts & $14 \%$ \\
\hline Miscellaneous & $13 \%$ \\
\hline Electronics & $9 \%$ \\
\hline
\end{tabular}

Source: Freight watch 2011.

\subsubsection{Human factor}

This factor refers to complicity of employees inside the companies with criminals, by leaking information on the shipments. It is hard to identify this factor with statistic data, being mentioned only by an $11 \%$ of the interviewed entrepreneurs, who referred just to the vehicle's driver However, all the SCRM experts agreed on the relevance of this factor, placing it on the first place with the greatest weight. Entrepreneurs consider the driver's complicity, assuming he pretends that merchandise was stolen in order to sell it. This complicity could also come from office personnel knowing information on the shipments.

\subsubsection{Free or toll road}

According to experts, driving on toll-free highways increases the theft risk. Insurance companies require insuring the merchandise that in sections with toll road option this one be chosen, since other roads offer more ease to escape and hide the merchandises, unlike a toll road with surveillance and controlled access. 


\subsection{Relevant factors and its weighing}

The list of risk factors obtained from the experts, with the weightings after applying the Delphi Method is shown in Table 3. These weightings reflect the agreement between experts about the relevance of factors.

Table 3: $\quad$ Significant factors.

\begin{tabular}{ll}
\hline Factor & Weightings \\
\hline Human factor & 44.93 \\
\hline Type of product & 43.48 \\
\hline Zone & 6.52 \\
\hline Toll road vs. free & 2.90 \\
\hline Vehicular configuration & 2.17 \\
\hline
\end{tabular}

\subsection{Impact identification}

On the first impact evaluation of shipments theft, all entrepreneurs mentioned the economic value of the lost merchandise. However, some of them recognized other relevant impacts aside of the value of merchandise, but they do not have completely identified or quantified these impacts. The impact magnitude depends on the product features. Below are proposed the dimensions which can measure the impact of the theft to companies.

\subsubsection{Loss of the brand}

Mainly, for specialized goods, brand value is present. This feature differentiates a product from others; Mariotti [24] proposes the concept of brand value, Kapferer [25], in turn, distinguishes between brand value and product value.

Since customer expectations are based on the brand value, and stolen products may be damaged or contaminated, this can cause an irreparable damage to the brand value. Besides, stolen product is a competence for the same company due the selling in the grey market by a fraction of its price.

\subsubsection{Non-compliance to the customer}

The non-compliance to the customer may have implications going from a penalization by the retailer up to losing the customer permanently. This impact was only mentioned by some entrepreneurs due to penalizations; however their estimation depends on their accumulated sum, sometimes based on the estimated profit lost or by having an empty shelf. Experts considered the non-compliance to customer to have the highest impact, followed by the loss of market and brand. 


\subsubsection{Loss of market}

The loss of market associated with the unsatisfied demand is very hard to estimate. Principally for the commodities, as Bonta and Farber [26] define, "Commodities are products of identical technologic nature which means that there is no differentiation at all between two products while they are of the same category or class". That is why goods can be replaced by another brand, with the chance that the customer will prefer the new brand in his (her) next buy.

\subsubsection{Required time to newly resupply the stolen product}

Lean manufacturing systems have allowed companies to operate with minimal inventories with a relative flexibility, to face the market fluctuations. However, in some supply chains of high complexity, the loss of a shipment may become practically irretrievable, especially if it is the release of a new model, product or simply of season.

\section{Conclusions}

The first conclusion is that the route is not a key factor in the theft risk, as change course to reduce theft is not effective in long term. Instead, type of goods is a factor in the risk of theft and possibly is one of the most important factors.

One important factor not considered at the beginning of this study, was the lack of control of the company's staff to prevent leakage of information. This validation should not only apply to truck drivers. Equally important is to diagnose within companies and identify personnel with access to confidential information about shipments. Additionally, experts agree that computer must implement procedures to ensure data integrity and prevent theft of data by third parties.

The method proposed on this study presents advantages over the traditional methodology of risk management which is based on identify and prioritizing risk according to subjective estimations of impact. The study proved the assertion by Puljić [20]: "there are certain cognitive biases that lead to individual managers to overestimate their own knowledge, skills, and their ability to influence circumstances in which they work and make their decisions. This is of particular importance in the management of Supply Chain Risk, as the perception of risk and the decisions how to deal with it are highly dependent on the individual interpretation of the situation and the psychological attitudes of the decision maker".

Furthermore, the present study identifies factors that influence risk facilitates decisions to determine effective measures of risk prevention and impact mitigation. Although this proposal has been made to address the problem of freight theft in Mexico, this methodology can be used to study the risks in the supply chain when statistical information is insufficient to support decisionmaking. 


\section{References}

[1] Sheffi, Y., Supply chain management under the threat of international terrorism. The International Journal of Logistics Management, pp. 1-11, 2001.

[2] Martha, J., and Subbakrishna, S., Targeting a just in case supply chain for the inevitable next disaster. Supply Chain Management Review, 6 (5) pp. 18-23, 2002.

[3] Lee, H., and Wolfe, M., Supply chain security without tears. Supply Chain Management Review, 7(1), pp. 12-20, 2003.

[4] Lee, H., and Whang, S., Higher supply chain security with lower cost. Lessons from total quality management. GSB Research Paper 1824, Stanford Graduate School of Business, Stanford University. 2003.

[5] Lewis, B., Erera, A., and White, C., Optimization approaches for efficient container security operations at transshipment seaports. Transportation Research Record (1822), pp. 1-8, 2003.

[6] Luedtke, J., and White, C., The Value of Asset Visibility in the supply Chain: Single and Dual Source Models. IEEE Conference on systems, man and cybernetics: proceedings, 89-94, 2004.

[7] Bainman, S., Netessine, S., and Kunreuther, H., Procurement in supply chains when the end products exhibits the "weakest link" property. The Wharton School, University of Pennsylvania, 2004.

[8] Willis, H., and Ortiz, D. Evaluating the security of the global containerized supply chain. Santa Monica, CA., Rand, 2004.

[9] Tsamboulas, D., and Moraiti, P., Identification of potential target locations and attractiveness assessment due to terrorism in the freight transport. Journal of Transportation Security, 1(3), 2008.

[10] Chopra, S., and Sodhi, M., Managing risk to avoid supply chain breakdown, MIT Sloan Management Review, Fall, 53-61, 2004.

[11] Uhlig, S., Managing disruptions in transportation systems. University Maastricht, Faculty of Economics and Business Administration, Netherlands, 2008.

[12] Wilson, M., The impact of transportation disruptions on supply chain performance. California, Elsevier, 2007.

[13] Tsuchiya, S., Tatano, H., and Okada, N., (2007). Economic Loss Assessment due to Railroad and Highway Disruptions. Economic Systems Research, 147-162, 2007.

[14] Huang, H., Chou, Y., and Chang, S., A dynamic system model for proactive control of dynamic events in full-load states of manufacturing chains, International Journal of Production Research, 1-22, 2007.

[15] Takahashi, A., Ando, A., and Mun, S., Estimation of the Economic Damages Caused by the Hanshin-Awaji Great Earthquake. Infrastructure Planning Review, 14, pp. 149-156, 1997.

[16] Okuyama, Y., Hewings, G., and Sonis, M., Measuring Economic Impacts of Disasters: Interregional Input-Output Analysis Using Sequential Inter industry Model, Y. Okuyama, and S.E. Chang (Eds.) 2004. 
[17] Rodrigues, V., Stantchev, D., Potter, A., Naim, M., and Whiteing, A., Establishing a transport operation focused uncertainty model for the supply chain. International Journal of Operations and Production Management, 388-411, 2008.

[18] Cedillo, G., Primera encuesta nacional, Evaluación del riesgo en la cadena de suministro. Nuevo León, Mexico, CONACYT, 2011.

[19] Li, X., Chandra, C., and Shiau, J.-Y., Developing taxonomy and model for security centric supply chain management. Michigan: Department of industrial and manufacturing systems engineering, University of Michigan, 2008.

[20] Puljić, M., The influence of cognitive biases on managerial perceptions. The 10th International Research Seminar. United kingdom: Loughborough University, UK, 2010.

[21] Jessup, E., Monson, G., and Kasaban, K., A feasibility Study evaluating transportation security systems and associated multi-modal efficiency impacts. School of economic science Washington State University., Transportation Northwest (trans now), Department of civil Engineering, 2006.

[22] Recurso Confiable, Theft statistics 2010. Retrieved 08-20-2011, from Recurso Confiable: http://www.recursoconfiable.com/rep_sin_state.asp, 2011.

[23] Freight Watch, Annual report Mexico cargo theft: 2010. Austin, Texas. Freight Watch, 2011.

[24] Mariotti, J., Smart things to know about, brands and branding. Milford, USA. Capstone USA, 2001.

[25] Kapferer, J., The new strategic brand management: Creating and sustaining brand equity long term (Fourth ed.). Kogan page, 2008.

[26] Bonta, P., and Farber, M., 199 Questions about marketing, Bogotá, Colombia: Norma, 1994. 